\title{
Arbor
}

\section{La nutrición del deportista}

\author{
José María Odriozola Lino
}

Arbor CLXV, 650 (Febrero 2000), 153-170 pp.

Comemos para reponer el desgaste diario de las estructuras corporales y pérdidas de reservas energéticas. Un deportista debe comer más que un sedentario, porque gasta más. La calidad nutricional debe tener las adecuadas proporciones de carbohidratos, proteinas y grasas, que irán acompañadas por vitaminas, minerales y fibra. El agua es el nutriente más importante y el deportista debe cuidar especialmente su rehidratación.

El reparto de las comidas debe armonizarse con la actividad física, para evitar problemas digestivos. Cuanto más variada sea la dieta, más correcta será la reposición nutricional. Hay que comer de todo, aunque de unas cosas más que de otras. Si se come suficiente en cantidad y con la calidad adecuada, no hará falta tomar suplementos nutricionales.

La alimentación sirve para reponer las pérdidas que la actividad diaria ocasiona en nuestro organismo. En los jóvenes en edad de crecimiento, sirve además para contribuir con los materiales necesarios para su desarrollo corporal.

La composición del cuerpo humano de un hombre adulto de unos $70 \mathrm{Kg}$. de peso y que se encuentre en forma física normal, estará constituida mayoritariamente por unos $28 \mathrm{Kg}$. de músculo esquelético, unos $12 \mathrm{Kg}$. de tejido adiposo, unos $10 \mathrm{Kg}$. de esqueleto, cerca de 5 $\mathrm{Kg}$. de piel, 1,8 Kg. que pesará el hígado, 1,4 Kg. el cerebro y alrededor de 325 gr. el corazón y los riñones. Si esto lo traducimos ahora a macromoléculas, tendría alrededor de $43 \mathrm{~kg}$. de agua (aproximadamente el 62\%), algo menos de $12 \mathrm{~kg}$. de proteínas (el 17\%), unos 9,7 kg. de 
grasa (casi el 14\%), alrededor de 4,3 kg. de minerales (el 6,1\%) y algo más de $1 \mathrm{~kg}$. de carbohidratos (el 1,5\%).

De todo ello, puede llegar a perder, sin riesgo grave para su salud, hasta un $10 \%$ de agua, hasta un $30 \%$ del contenido mineral del esqueleto, unos $2 \mathrm{~kg}$. de proteínas, unos 200-300 grs de carbohidratos (de sus reservas de glucógeno) y prácticamente todos sus depósitos grasos, salvo aproximadamente $1 \mathrm{~kg}$. que resulta esencial para las estructuras corporales.

Por tanto, diariamente comemos para mantener nuestra capacidad vital, regenerar las estructuras degradadas y realmacenar las reservas energéticas. Para que la alimentación resulte adecuada a los requerimientos de cada persona, hay que tener en cuenta la cantidad total de energía que gasta diariamente, la calidad nutricional de los componentes de los alimentos y como repartimos todo ello en las varias comidas o ingestiones de alimentos a lo largo del día.

En cuanto a las diferencias que puede haber entre la alimentación de un deportista y una persona sedentaria equivalente, existen sobre todo a nivel de la cantidad de energía (kilocalorías) que debe ingerir diariamente: como gasta mucho más tiene que comer mucho más. En la calidad, no debe haber grandes diferencias en relación con una persona sedentaria, pero que coma de forma adecuada y equilibrada. El reparto de comidas le acarrea al deportista el problema de compatibilizar digestión y entrenamientos o competiciones: no se puede hacer esfuerzos de una cierta intensidad con el estómago lleno.

Para la calidad de la alimentación, hay que tener en cuenta que los alimentos son todos mezclas de nutrientes energéticos y no energéticos. Los primeros son los que pueden proporcionar kilocalorías al ser degradados en nuestro organismo: son las proteínas, los azúcares o carbohidratos y los lípidos o grasas. Los no energéticos son necesarios para que el organismo funcione correctamente, pero no proporcionan kilocalorías: son el agua, las vitaminas, los minerales y la fibra.

El deportista debe reponer diariamente tantas kilocalorías como consume con sus actividades vitales y deportivas, ni más ni menos. Si come menos, podrá sufrir problemas de desnutrición que pueden ocasionar patologías. Si come de más, acumulará grasa innecesaria y el exceso de peso le acarreará pérdida de capacidad física. Para controlar una correcta ingesta de alimentos en lo relativo a la cantidad, el deportista debe mantener un peso relativamente constante y unas medidas antropométricas determinadas.

La calidad de la alimentación vendrá establecida por los porcentajes de kilocalorías que aporten los nutrientes energéticos. Si estos son 
correctos, el aporte en nutrientes no energéticos también será correcto, siempre que el deportista se hidrate adecuadamente. Para establecer esos porcentajes de aporte calórico entre proteínas, azúcares y grasas, hay que tener en cuenta algunos hechos. En primer lugar, el valor calórico de cada tipo de macromolécula energética: 1 gr de proteínas aporta 4 kilocalorías, lo mismo que 1 gramo de azúcares, mientras que las grasas aportan 9 kilocalorías por gramo. Por otro lado, las proteínas no se almacenan en el organismo como material energético de reserva, cosa que si es posible con las grasas y los azúcares. Pero mientras las primeras pueden acumularse de forma casi ilimitada, los azúcares solo se almacenan en forma de glucógeno, en músculos e hígado y de forma muy limitada, por hacerlo hidratados y ocupar mucho volumen.

Teniendo en cuenta todo ello y la propia estructura de esas macromoléculas energéticas, el porcentaje de aporte calórico al total de la ingesta diaria, deben proporcionarlo las proteínas en un $15 \pm 3 \%$, los carbohidratos en un 55-60\% y las grasas el resto, siempre a ser posible menos del $30 \%$

\section{Metabolismo de las proteínas. ¿Es necesaria una sobrealimentación protéica en los deportistas?}

Las proteínas son unas macromoleculas que forman parte de las estructuras corporales, permitiendo que nuestro organismo realice un gran numero de funciones. Las hay formando parte inherente a la morfología celular y otras que pueden moverse a lo largo de nuestro cuerpo. Además pueden tras degradarse, producir calorías (como se ha dicho, aproximadamente 4 Kcalorías por gramo), aunque no se almacenan como reserva energética. Deben constituir en un deportista, el segundo componente mayoritario de nuestro cuerpo, después del agua, en porcentajes que variaran según el sexo, la talla la edad, etc., pero que pueden llegar a estar cerca del $20 \%$ del total corporal.

Otra característica de las proteínas es que tienen una vida media funcional bastante corta, en general. Por ello, se utilizan y se degradan con gran rapidez. Existe un continuo recambio proteico en el cuerpo humano, es decir gran parte de las proteínas que lo forman se desnaturalizan tras actuar un determinado numero de veces, y deben sintetizarse de nuevo inmediatamente, para mantener nuestra capacidad vital. 
Diariamente recambiamos la mayoría de las proteínas y por suerte unas 3/4 partes de los componentes ( los aminoácidos ) de sus largas cadenas polipeptídicas, se reciclan, reutilizándose de nuevo para construir nuevas cadenas. Pero el otro $25 \%$ de los aminoácidos son metabolizados a otras moléculas nitrogenadas necesarias en el organismo (bases púricas y pirimidinicas, poliaminas biogenas ) o son excretadas en forma de urea. El esqueleto carbonado de esos aminoácidos se utiliza como material convertible en calorías y es oxidado casi totalmente con ese fin.

Por tanto, necesitamos reponer diariamente un $25 \%$ de las necesidades proteicas de nuestro cuerpo, que nos permitan refabricar todas las proteínas que lo constituyen. Como no se pueden almacenar, esa será la cantidad suficiente y necesaria, pero como hemos dicho variable en cada persona, según su somatotipo, pero también según su actividad vital.

Como referencia inicial, se admite que un adulto, debe ingerir entre 0.8 y 1.0 gramos de proteína pura y de valor biológico 100, por Kgr. de su peso corporal. Con eso se mantendría el balance de nitrógeno equilibrado, cuya única fuente en los alimentos la constituyen las proteínas, y que es fundamental para el mantenimiento de la composición corporal de las mismas. Es decir, una persona de $70 \mathrm{Kgrs}$. de peso, necesitaría entre 60 y 70 grs. de proteínas en su dieta diaria. Como los alimentos tienen distinto \% de estas macromoleculas en su contenido (la carne o las lentejas alrededor del 25\%), es por lo que se habla de proteína pura. Lo del valor biológico viene condicionado porque no todas las proteínas contienen al 100 por 100, los llamados aminoácidos esenciales (la mitad de los veinte que forman todas las cadenas polipeptídicas y que no pueden ser fabricados endógenamente por el organismo, por lo que deben ser ingeridos necesariamente en la dieta). Se toma el huevo de gallina, como referencia para el valor biológico $100 \mathrm{y}$ en general todas las proteínas de origen animal lo tienen. Pero no así las de origen vegetal, mas sanas porque los alimentos que las contienen tienen menos grasas, pero insuficientes en si mismas para proveer de todos los aminoácidos necesarios para una correcta reposición proteica. Un vegetariano estricto (veganista) tendría que mezclar hábilmente distintos tipos de vegetales en sus comidas, para compensar la falta de esos aminoácidos esenciales en unos con la presencia en otros (por ej. frijoles con arroz).

Volviendo a esas cifras de referencia, 0.8-1.0 grs. por $\mathrm{Kg}$. de peso corporal, equivaldrían en general al $15 \%$ del total de las calorías ingeridas diariamente por una persona. Un deportista, como gasta mucha 
energía con el ejercicio, necesita comer mas. Puede llegar a duplicar o triplicar, lo que su metabolismo basal gastaría para mantener su vitalidad corporal. Podemos pasar de 1.500 Kcalorías, a 3.000-5.000 o incluso 8.000, en una dura etapa ciclista. Por tanto, al comer mas, el deportista si mantiene ese $15 \%$ del equivalente calórico que aportan las proteínas, ya está ingiriendo mas que ese 0.8-1.0 gr. por $\mathrm{Kg}$. mencionado. En el caso de dietas hipercalóricas, habría que rebajar ese $15 \%$ en un aproximadamente $3 \%$ (al 12\%) al igual que en las hipocalóricas habría que subirlo en igual \% (al 18\%). Es cierto por otro lado, que el deportista necesita mayor cantidad de proteínas que una persona sedentaria equivalente, para poder mantener su capacidad de reconstrucción de las estructuras proteicas degradadas diariamente. $\mathrm{Y}$ ello, sencillamente, porque las utiliza mas y acorta su tiempo de recambio. Es decir destruye mas proteínas al entrenar y debe fabricarlas de nuevo. Provoca con ello un incremento en la excreción de nitrógeno, que habrá que compensar con una mayor ingesta.

\section{¿Se pueden cuantificar estas necesidades extra del deportista?}

Como ya hemos comentado, hay dos factores que incrementan la cantidad de proteínas que deben tomarse en la alimentación, cuando se hace ejercicio. La actividad física provoca un mayor «desgaste» de las proteínas funcionales del organismo, pero también con frecuencia, sobre todo si se trata de actividad aeróbica prolongada, un mayor uso de las proteínas como fuente de energía, que pueden llegar a contribuir al gasto total de calorías desde un 5 a un 15\%. Para esto se utilizan sobre todo los aminoácidos ramificados (leucina, isoleucina, valina) que previa conversión a alanina por transaminaciones, entran en la ruta oxidativa aeróbica con su esqueleto carbonado para generar ATP.

El otro factor que demanda mas proteínas en la dieta, es que como consecuencia del entrenamiento y de forma especifica y localizada, allí donde se destruyen mas estructuras proteicas al trabajar físicamente, se reconstruyen durante el reposo, las mismas estructuras pero siempre con un pequeño incremento: el efecto «rebote» que es la ganancia en capacidad física como consecuencia del entrenamiento. Para ello hará falta tiempo de recuperación y materia prima, es decir mas aminoácidos para esa resíntesis proteica. Ambos factores son los responsables de esas mayores necesidades del deportista, en cuanto a proteínas se refiere. 


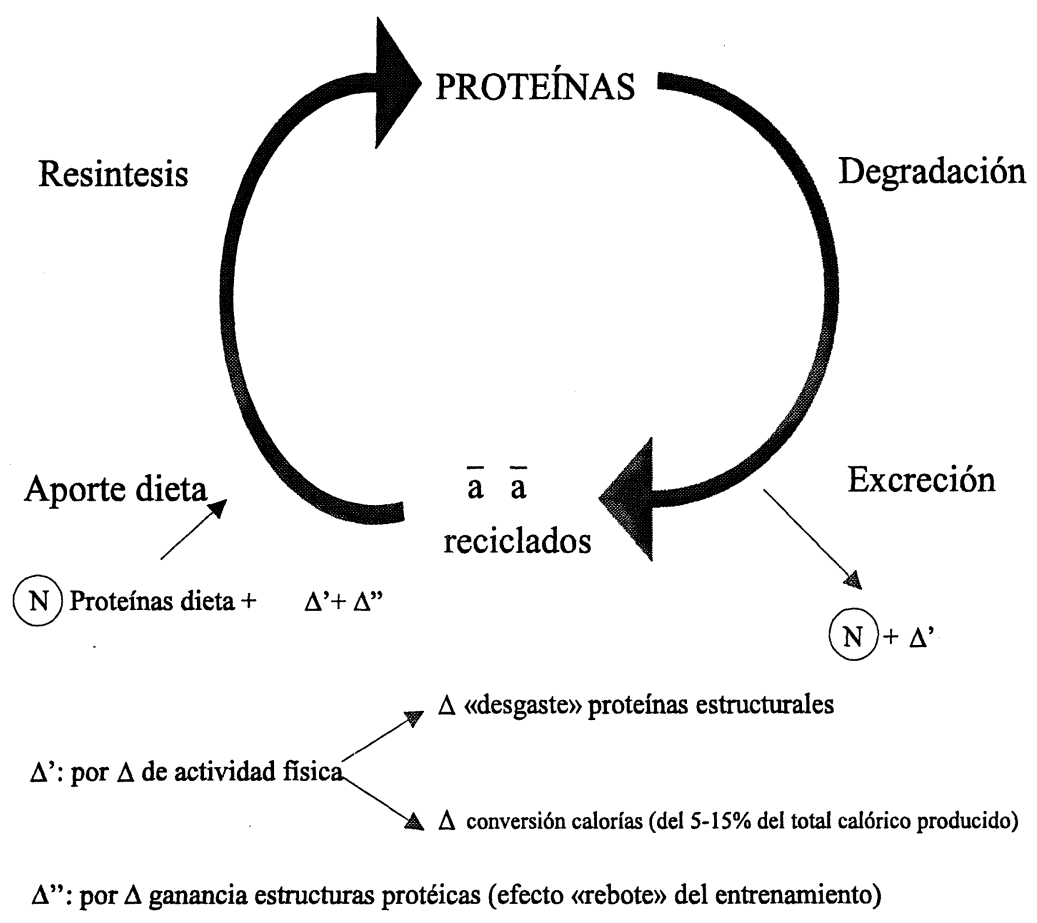

Hay que diferenciar entre distintos tipos de especialidades deportivas. En deportes de fuerza, donde hay sobre todo una hipertrofia muscular, como consecuencia del aumento de proteínas contráctiles, se calcula que será necesario tomar entre 1.5 y 2.0 grs. por $\mathrm{Kg}$. de peso corporal, diariamente. Es decir, hasta el doble de lo normal, en una persona sedentaria. En deportes de resistencia, donde el incremento es más orientado al aumento de la dotación de sistemas enzimáticos y transportadores, será necesario tomar entre 1.2 y 1.5 grs. de proteínas por $\mathrm{Kg}$. de peso corporal.

Todo lo que exceda de esas cantidades, no provocará una mejora en el rendimiento del deportista, puesto que al no poder almacenarse, deberán ser excretadas o metabolizadas a otras moléculas y ello es costoso y nada conveniente para el organismo. Parte del exceso puede convertirse en grasas que se almacenarán de forma innecesaria. Además pueden provocar incremento de ácido úrico en sangre, desmineralización del esqueleto, deshidratación etc. Por tanto, no hay que suplementarse con proteínas o aminoácidos sintéticos, si no hay déficit en su ingesta dietaria. Si faltan en cantidad suficiente, no podremos regenerar las estructuras degradadas y perderemos capacidad física. Eso sucede a veces cuando se hacen dietas de adelgazamiento; a la vez que se sigue 
entrenando. Se pierde antes glucógeno, agua y proteínas que grasas. Pero un exceso de proteínas sobre lo necesario no es positivo y es insalubre.

\section{Contenido idóneo de carbohidratos en la dieta del deportista}

Por las razones ya comentadas, el almacenamiento de glucógeno en el organismo es limitado a unos cuantos cientos de gramos entre el hígado y el músculo esquelético. Como es el combustible metabólico más usado por los deportistas, las reservas corporales se vacían total o parcialmente a diario. Por ello habrá que asegurarse de reponerlas ingiriendo azúcares complejos, para evitar un agotamiento prematuro al hacer ejercicio, por falta de glucógeno. Ello es lo que justifica que casi $2 / 3$ de las calorías que tomamos con los alimentos, deben ser carbohidratos.

Como no todos los carbohidratos se absorben con igual rapidez, tenemos que distinguir entre sus índices glucémicos (Tabla 1). Estos definen la velocidad con que cambian la glucemia sanguínea (concentración de azúcares en sangre) al ser absorbidos, parámetro que el organismo debe mantener siempre lo más constante posible para evitar hiper o hipoglucemias, de consecuencias fatales. Los llamados simples, son los de alto índice glucémico (glucosa, sacarosa), que son rápidamente absorbidos. Los complejos, son los de bajo o medio índice glucémico (almidón), que son los idóneos para ser convertidos en glucógeno al ser asimilados. Un exceso de azúcares simples, puede contribuir a un incremento de las reservas grasas, en forma de triglicéridos, en el tejido adiposo.

El índice glucémico de un azúcar natural puede modificarse a la alza con la maduración (caso de muchas frutas) y con la cocción (caso de la pasta, el arroz, etc.). De una manera práctica, debemos pensar que en la dieta diaria del deportista, debe haber al menos 5 gramos de carbohidratos (de los que el $90 \%$ deben ser complejos), por kilogramo de peso corporal. Si se pretende hacer la dieta de supercompensación de carbohidratos, para incrementar hasta el máximo posible las reservas de glucógeno, previamente a esfuerzos largos, continuados e intensos, se puede incrementar esa cantidad diaria hasta 7-8 gramos por kilogramo de peso corporal. Hay que beber mucha agua a la vez, porque el glucógeno se almacena totalmente hidratado $(3 \mathrm{ml}$. de agua por cada gramo de glucógeno). Con ello se pueden llegar a duplicar las 
reservas normales y retrasar la aparición de la fatiga en esos esfuerzos prolongados (de más de 90 minutos).

La toma de azúcares, en los momentos previos a una competición o entrenamiento, no es claramente recomendable. En muchas personas y según las circunstancias (hora del ejercicio, ingesta alimentaria anterior) puede ser contraproducente al provocar lo que se denomina un «rebote insulínico», que podría ocasionar hipoglucemia durante el ejercicio. Por ello, de tomar azúcares en la hora anterior al comienzo del ejercicio, deben ser de los del tipo complejo (de índice glucémico bajo) para minimizar la secreción de insulina. Si durante el calentamiento previo a la prueba, se ingieren bebidas para mantener la hidratación corporal de forma adecuada, se pueden incluir azúcares de alto índice glucémico, para compensar el gasto producido por esos ejercicios de calentamiento. Ya no habrá secreción insulínica, pues ésta se interrumpe al hacer ejercicio. Para asegurarnos este importante aporte de carbohidratos en nuestra dieta diaria, debemos incluir la ingesta diaria de cereales y frutas, así como de algunas raciones de verduras, legumbres, pasta o arroz en las comidas.

TABLA 1. Alimentos que contienen carbohidratos

1) CON ALTO INDICE GLUCEMICO

$\begin{array}{ll}\text { CEREALES } & \text { Pan blanco } \\ & \text { Pan integral } \\ & \text { Pan de centeno } \\ & \text { Arroz } \\ & \text { Muesli } \\ & \text { Cereales desayuno de trigo - maíz } \\ & \text { Galletas } \\ \text { VEGETALES } & \text { Maíz } \\ \text { FRUTAS } & \text { Habas } \\ & \text { Patatas } \\ \text { AZUCARES } & \text { Pasas } \\ & \text { Plátanos } \\ & \text { Glucosa } \\ & \text { Maltosa } \\ \text { Miel } \\ \text { CON INDICE GLUCEMICO MODERADO } \\ \text { CEREALES } & \text { Sacarosa } \\ & \text { Maltodextrina } \\ & \text { Espaguetti } \\ & \text { Macarrones } \\ & \text { Fideos } \\ \text { Harina de avena } & \text { Bizcochos }\end{array}$




\section{La nutrición en el deportista}

$\begin{array}{ll}\text { FRUTAS } & \text { Uvas } \\ & \text { Naranjas } \\ \text { 3) CON BAJO INDICE GLUCEMICO } & \\ \text { FRUTAS } & \text { Manzanas } \\ & \text { Dátiles } \\ & \text { Melocotones } \\ & \text { Ciruelas } \\ & \text { Cerezas } \\ \text { LEGUMBRES } & \text { Lentejas } \\ \text { AZUCARES } & \text { Garbanzos } \\ \text { PRODUCTOS LACTEOS } & \text { Fructosa } \\ & \text { Helado } \\ & \text { Leche } \\ & \text { Yogurt }\end{array}$

SOPA DE TOMATE, JUGO DE MANZANA

\section{Las grasas en la dieta del deportista}

Como ya se ha dicho, su aporte calórico no debe sobrepasar el $30 \%$ del total. En general, las grasas incrementan la palatibilidad de las comidas y no se trata tampoco de intentar eliminarlas totalmente de los alimentos que ingerimos. Hay que tener cuidado con los alimentos que usamos para cocinar o condimentar. Añadimos con frecuencia grasas animales, aceites o salsas de alto contenido lipídico (mahonesas por ejemplo) a casi todo. Ello es lo que puede subir ese porcentaje diario que no es deseable en el deportista, por innecesario nutricionalmente y porque contribuye a un peso excesivo de materia grasa que hace de lastre para la actividad física. Como ya hemos comentado, también un exceso de azúcares simples o proteínas, puede ocasionar un aumento de las reservas grasas en el tejido adiposo.

Un deportista debe intentar mantener unos índices de grasa corporal, por debajo del $12 \%$ en hombres y del $15 \%$ en mujeres. Hay especialidades deportivas en que eso se reduce a la mitad (maratonianos, esquiadores de fondo, ciclistas de ruta), sin ningún menoscabo de su capacidad física. Desde el punto de vista nutricional, solo necesitamos asegurar una ingesta diaria de dos ácidos grasos esenciales (no fabricables por el organismo) que son el linoleico y el linolénico, precursores del araquidónico y éste de las prostaglandinas, tromboxanos y leucotrienos, de gran importancia en la buena funcionalidad de nuestro cuerpo. Las cantidades que se necesitan son muy pequeñas y se consiguen cqn una alimentación correcta. 
Hay que evitar el exceso de grasas saturadas (no más del $10 \%$ del total lípidico) y de colesterol, como en cualquier persona que coma de forma adecuada para su salud. Las mejores son los aceites con grasas monoinsaturadas (de oliva por ejemplo) que favorecen la circulación sanguínea.

\section{La rehidratación del deportista}

El agua es el principal componente del cuerpo humano, pues aporta entre el 60 y $65 \%$ del peso de un adulto, en condiciones físicas normales. Ello da idea de la importancia de mantener nuestro organismo perfectamente hidratado. Como diariamente perdemos varios litros de agua debido a la sudoración, la respiración, la orina y las heces fecales, debemos beber para reponerla y evitar problemas de mal funcionamiento de los sistemas corporales. Un deportista tiene todas esas vías de deshidratación incrementadas, debido al ejercicio diario y por ello debe beber mucho más que una persona sedentaria. Y debe hacerlo aunque no tenga sed, puesto que esta sensación, controlada desde el hipotálamo, solo se dispara cuando ya estamos algo deshidratados (eliminado el líquido que equivale a aproximadamente el $1 \%$ del peso corporal).

Sin embargo, las pérdidas de agua de nuestro cuerpo pueden ser tan elevadas al hacer ejercicio (hasta 1,5 - 2 litros por hora), que su reposición resulta difícil y solo podrá compensarse parte de las mismas. Por ello es fundamental comenzar los entrenamientos y competiciones perfectamente hidratados y beber desde el comienzo del esfuerzo, a intervalos adecuados y en cantidad suficiente.

Si no lo hacemos, iremos perdiendo capacidad física que se traducirá en calambres musculares, tras pérdidas de los fluidos internos que equivalen al 2-3\% del peso corporal. Si la deshidratación aumenta por encima del $8 \%$, se podría producir incluso una muerte súbita por un "golpe de calor" (la temperatura corporal sube por encima de los $42^{\circ} \mathrm{C}$ ) o por un «agotamiento por calor» (la tempèratura baja a menos de $35^{\circ} \mathrm{C}$ ).

Para evitar esos problemas, hay que beber agua sola o con adecuados tipos de solutos, antes, durante y después de hacer ejercicio. Sobre todo cuando el ejercicio es intenso y continuo durante más de 30 a 45 minutos, o incluso de menor intensidad, pero se hace durante más de 90 minutos.

Como pauta de conducta adecuada, se recomienda ingerir 1 mililitro de agua por cada kilocaloría de energía ingerida con los alimentos 
sólidos, cada día. Estos contienen también agua (aproximadamente la mitad de su contenido), por lo que tendremos que bebernos el resto, en forma líquida.

Cuando se va a hacer un esfuerzo de las características comentadas, conviene beber previamente e incluso durante el calentamiento de las competiciones entre 300 y $500 \mathrm{ml}$ de agua, conteniendo entre 60 y 80 gramos de azúcares. Cuanto más cerca del comienzo de la carrera, mejor (hasta 5 - 15 minutos antes) para evitar la necesidad de orinar y el posible efecto «rebotẹ» de hipoglucemia debido a la secreción de insulina.

Durante el ejercicio, siempre las pérdidas serán mayores que las posibles reposiciones. Pero para minimizar la deshidratación, hay que beber cada 15 - 20 minutos unos 250 - $300 \mathrm{ml}$ de bebidas hipotónicas, para facilitar su rápida absorción intestinal, más lenta cuanto más intenso sea el ejercicio. El agua puede llevar entre 40 y 80 gramos de una mezcla al 50\% de glucosa y fructosa, con entre 0,4 y 1,2 gramos de sodio (que facilita la absorción de los azúcares), todo por litro de líquido. Debe ser fresca y sin carbonatación (burbujas). Todo esto es lo recomendable de forma estándar. Pero cada corredor debe probar lo que le va mejor, pues hay variaciones según la capacidad de absorción de cada uno. Hay que probarlo en entrenamientos y practicar la forma de beberlo, mejor de golpe y no a sorbitos, para facilitar su más rápida absorción y evitar «tragar» mucho aire que puede acabar produciendo flato.

En invierno, con frío, pueden tomarse bebidas templadas o incluso calientes, con mayor contenido en azúcares (maltodextrinas o almidón soluble), pues la urgencia de la hidratación no es tan grande.

$\mathrm{Al}$ terminar el ejercicio hay que reponer líquidos lo más rápidamente posible y durante mucho tiempo. A veces, tras un maratón, por ejemplo, cuesta hasta 24 horas el que el cuerpo vuelva a sus niveles óptimos de contenido acuoso. Mientras la orina no sea incolora, hay que seguir bebiendo, porque es síntoma de deshidratación. Cualquier tipo de bebida es válido (zumos de fruta, bebidas refrescantes, agua con azúcares) salvo si contienen alcohol. La cerveza es para disfrutarla, no para rehidratarse, pues es diurética y produce la necesidad de orinar con frecuencia y por tanto perdemos más líquido.

Un deportista debe estar siempre correctamente hidratado. Es el aspecto más importante de nuestra nutrición y a veces el más descuidado. Hay que beber siempre, agua por supuesto, aunque no se tenga sed. El cuerpo lo agradecerá y se harán mejores marcas. 


\section{Ingesta de minerales en el deportista}

- Los minerales no pueden ser generados por el propio cuerpo y por tanto hay que reponer diariamente las pérdidas que en el mismo ocasiona la actividad vital. Excretamos ciertas cantidades de minerales y si no son compensadas no podemos rendir al máximo o incluso se ocasionarán patologías. Sin embargo las dosis diarias de estos oligoelementos que deben ser ingeridos formando parte de los alimentos son pequeñas, aunque algunos se absorben a través del intestino de forma poco eficaz. Por ello necesitamos solo algunos gramos diarios de electrolitos o sales como sodio, potasio, calcio, magnesio y cloro, además del fósforo, para que todas las pérdidas queden compensadas. De otros tan importantes como el hierro, el zinc o el cobre, solo nos harán falta miligramos, y del resto como el cromo, el selenio, el flúor o el boro solo microgramos.

Sin embargo, aunque parezcan por estos bajos niveles de reposición, que debe resultar fácil evitar posibles déficits con una alimentación sana y equilibrada, hay con frecuencia en los atletas, problemas ocasionados por la falta de suficiente entrada en el organismo de hierro y calcio. Esto puede provocar patologías que pondrían en peligro la capacidad física del atleta como anemias y osteoporosis, respectivamente. La causa fundamental es la falta de suficiente contenido de esos minerales en la dieta del deportista, el incremento de excreción de los mismos, como consecuencia del ejercicio o de otros factores, y dificultades en la absorción a través del intestino.

HIERRO: Aunque el cuerpo de un adulto sólo contenga entre 3 y 5 gramos de hierro en total, su importancia en multitud de rutas metabólicas hace que pequeños déficits en su disponibilidad afecten a funciones vitales, como el transporte de oxígeno en la sangre o la obtención de energía en el músculo.

Tenemos para evitarlo reservas de hierro en depósitos profundos unidos a proteínas como la ferritina o la hemosiderína. Estas ceden parte de esas reservas cuando por falta de reposición dietaria, baja la cantidad de hierro disponible para la hemoglobina de los glóbulos rojos y se produce anemia, con la consiguiente pérdida de capacidad aeróbica. Pero esa generosa compensación acaba rebajando esos depósitos, que ocasionan un déficit de hierro que afecta a muchas enzimas necesarias para el metabolismo energético muscular. Eso se puede detectar por el test de ferritina, que «refleja» los contenidos de los depósitos profundos. Para evitar todos estos posibles problemas, bastará con asegurarse una correcta ingestión de hierro (800 miligramos en hombres, 
casi el doble en mujeres con menstruación) contenido en muchos alimentos como carnes, pescados, legumbres, verduras de hoja oscura ... El alimento con mayor porcentaje de hierro es la morcilla, que contiene sangre de cerdo, con su hemoglobina correspondiente.

Si por los análisis de sangre que periódicamente (pero sin exagerar) se le deben hacer a un deportista, se comprueba que tiene tendencia a estar bajo de hemoglobina o ferritina sérica, en determinadas épocas del año (por mayor volumen de entrenamiento por ejemplo) se le pueden administrar, por vía oral, suplementos de hierro, siempre bajo prescripción facultativa. El automedicarse es peligroso, porque el exceso de hierro produce como mínimo estreñimiento, puede evitar la correcta absorción de otros minerales de la dieta (zinc, cobre) y en algunas personas provocar hemocromatósis (depósitos exagerados de hierro en el hígado y otros órganos vitales) que es mortal a corto plazo.

CALCIO: es el mineral más abundante en nuestro cuerpo, porque forma parte con el fósforo del componente mayoritario del esqueleto. Pero además tiene otras muchas funciones como regulador metabólico y sus niveles en el organismo son controlados de forma muy ajustada, pues pequeños déficits pueden provocar fallos en su funcionalidad. La contracción muscular, por ejemplo, necesita calcio para poder llevarse a cabo.

El esqueleto es como un gran reservorio de calcio, y si éste no entra con los alimentos en suficiente cantidad diaria, cede parte de su contenido para que el organismo pueda funcionar correctamente. Pero debido a esto se desmineraliza, se llena de burbujas de aire y se hace más frágil (osteoporosis, poros en los huesos). El atleta corre el riesgo de una fisura o fractura de esfuerzo, que exigirá un descanso total de semanas para reponerse, además de una suplementación de calcio, igualmente por vía oral.

El tomar al día el equivalente a tres vasos de leche (desnatada es más saludable), es suficiente para aportar el calcio que nuestro cuerpo necesita para reponer las pérdidas diarias.

La suplementación innecesaria de minerales no mejora la capacidad física del atleta y puede ocasionarle problemas secundarios en su metabolismo. Por tanto no hacerlo por rutina, solo si los análisis de los niveles corporales lo hacen recomendable para evitar déficits detectados.

\section{Las vitaminas en la dieta del deportista}

Las vitaminas, al igual que los minerales, son componentes nutricionales de los alimentos, que no aportan calorías para el gasto 
energético pero son fundamentales para su producción. Son el equivalente al aceite para un motor, que no sirve para su función de producir un trabajo mecánico, pero cuya falta lo dejaría sin lubricación y se griparía. El organismo humano no es capaz de fabricar las vitaminas y por tanto deben tomarse necesariamente en la dieta, diariamente, pero en cantidades pequeñas.

Su misión a nivel del metabolismo corporal es actuar de co-catalizadores, es decir ayudar a que las reacciones metabólicas catalizadas por las enzimas, se lleven a cabo de forma rápida y correcta. Si faltan, se produce avitaminosis y muchas reacciones se llevan a cabo lentamente o incluso no se hacen. Ello ocasiona perdida de eficacia de las funciones corporales o incluso patologías.

En una dieta suficiente en cantidad en relación con lo que gasta el organismo y con la adecuada calidad nutricional, no deben producirse déficits vitamínicos. Las vitaminas no se consumen durante las reacciones en las que actúan, pero si se van «desgastando» por el uso y se acaban degradando. Por ello hay que reponerlas a diario. Un deportista «desgasta» mas vitaminas que un sedentario, porque las usa mas, en su incrementado metabolismo energético. Pero como ingiere mas alimentos para compensar ese mayor gasto calórico producido por el ejercicio, ya estará tomando también mas vitaminas naturales. Es por tanto difícil que se produzca un déficit vitamínico, salvo que la calidad de la comida, es decir las debidas proporciones de proteínas, carbohidratos y grasas no sea la correcta, o que estos se procesen, cocinen o se tomen de forma que se destruyan las vitaminas que contienen.

Por tanto, el deportista no debería necesitar una suplementación vitamínica, si mantiene unos hábitos nutricionales adecuados, aunque gaste mas. Esa suplementación cuando es innecesaria, no solo no aumenta su capacidad física, sino que puede producirle algunos efectos secundarios negativos para su salud. Lo que en determinadas cantidades es bueno, en cantidades grandes (megadosis) es insalubre. Por tanto, la suplementación rutinaria no es recomendable, ni siquiera por el efecto "placebo» que puede originar.

\section{Tipos de vitaminas}

El termino «vitamina» lo inventó el polaco Casimir Funk en 1912, cuando estudiaba los efectos de la vitamina antiberibérica (B1), porque era una amina químicamente y daba vida (vita). Las 13 vitaminas 
especificas para humanos que hoy día se conocen, las clasificamos en dos grupos según su solubilidad, que refleja ciertas analogías estructurales: liposolubles (la A, D, E y K) e hidrosolubles (las del complejo B y la C). Nuestro organismo puede sintetizar algunas (niacina, $\mathrm{K}$ y D) pero no en cantidades suficientes, por lo que deben ingerirse diariamente con los alimentos.

Se recomiendan unas cantidades diarias estandar (RDA) fijadas según los conocimientos científicos actuales, necesarias para que las personas sanas y adultas mantengan su organismo funcionando correctamente. Pero habrá que tener en cuenta consideraciones individuales, de edad, sexo, actividad física, hábitos nutricionales o de consumo (tabaco, alcohol, grasas) así como la capacidad de absorción en el intestino de cada persona.

En cualquier caso, las cantidades medias que deben tomarse están en la tabla 2, y representan lo optimo para evitar carencias en adultos. Para prevenir otras malfunciones de nuestro cuerpo, quizás habría que aumentarlas y de eso hablaremos luego.

También conviene recordar que las vitaminas tienen efectos sinergisticos (acumulativos) entre ellas y con muchos minerales, de manera que tomadas juntas tienen mas capacidad funcional que individualmente.

TABLA 2

LIPOSOLUBLES

VIT. A (Retinol)

VIT. D (Calciferol)

VIT. $\mathrm{K}$ (Antihemorragica)

VIT.E(Tocoferol)

\section{HIDROSOLUBLES}

B1 (Tiamina)

B2 (Riboflavina)

B3 (Niacina)

B5 (Pantotenato)

B6 (Piridoxina)

B8 (Biotina)

B9 (Folato)

B12 (Cobalamina)

VIT. C (Ascorbato)
RDA(mgs./dia)

1

0.01

1

10

\section{5}

1.3-1.7

20

5-20

2-2.2

0.3

0.4

0.006

60-75 


\section{Vitaminas y radicales libres}

Además de la función que como ayudantes de las enzimas llevan a cabo las vitaminas en nuestro cuerpo, tienen varias de ellas un efecto antioxidante en las células humanas que es vital para defendernos de los radicales libres. Estos son especies químicas con electrones desparejados en su orbital exterior, que les dan una reactividad muy grande. Si no son bloqueados rápidamente, destruyen las membranas celulares provocando gran numero de patologías, entre ellas cáncer, demencia senil, diabetes, trombosis, cataratas, cirrosis y reumatismo.

Los radicales libres se producen internamente en nuestro organismo. Son como radiaciones que durante fracciones de segundo, unas 10000 veces al día, atacan las células. Por ello deben ser cotrarrestadas inmediatamente con antioxidantes, que bloqueen esos superóxidos, peróxidos hidróxilos $u$ óxigenos simples, para evitar su ataque a distintas estructuras celulares. Hay factores internos que incrementan su producción como el propio metabolismo energético. Un deportista tiene por ello aumentada la generación diaria de radicales libres de oxígeno, en función del consumo máximo de oxigeno así como de la duración e intensidad del ejercicio. Pero también tiene aumentadas sus defensas naturales por una adaptación metabólica al propio ejercicio: mas enzimas como la superóxido dismutasa, la glutation peroxidasa o la catalasa e incluso de ácido úrico que también es antioxidante. El uso indiscriminado e innecesario de medicinas también puede aumentar la formación de radicales libres. Por ello debemos asegurar la toma de vitaminas antioxidantes en la dieta, para bloquear su acción destructiva. Las más importantes son las $\mathrm{A}, \mathrm{E}$ y $\mathrm{C}$, además de los precursores de la A, los Carotenos y de los minerales Selenio y Zinc. Todos ellos tienen un efecto sinergistico entre si. Una dieta equilibrada y abundante, debería satisfacer plenamente todas estas necesidades en vitaminas y minerales.

Pero hay circunstancias que pueden incrementar los requerimientos de antioxidantes como el hecho de ser fumador, alcohólico, tomar mucho café, los antibióticos o vivir en ambientes muy polucionados, sobre todo con restos de productos químicos industriales. También el propio ejercicio físico, como hemos dicho, puede provocar la necesidad de un mayor aporte de estos antioxidantes. Pero al comer más porque gastamos más calorías, siempre que esa dieta sea variada y correcta, lo conseguiremos. Si necesitáramos suplementación artificial, hay que tener en cuenta que las megadosis de vitaminas pueden llegar a ser tóxicas. 
Cantidades de más de 10 veces las RDAs para las liposolubles y de más de 50 veces las RDAs para las hidrosolubles, son peligrosas.

Hay también que tener en cuenta que las vitaminas en general, sobre todo las hidrosolubles, son sensibles al calor, por lo que la preparación de las comidas destruye muchas de sus propiedades. También la luz o el contacto con el aire (como cuando exprimimos frutas para zumos) las afectan, rebajando su efectividad. El procesamiento de cereales y otros alimentos, elimina muchas vitaminas del complejo B, que luego se suelen añadir en las preparaciones comerciales.

Por tanto, para contrarrestar el efecto de los radicales libres y rebajar su generación, hay que evitar las calorías innecesarias y las sustancias que favorecen su producción (alcohol, tabaco, polución química ambiental, grasas poliinsaturadas en exceso). Además se debe tomar una dieta variada. equilibrada y que cubra nuestras necesidade: energéticas y si fuera necesario, bajo prescripción medica, suplementarla con antioxidantes vitamínicos y minerales. En la tabla 3 damos unas orientaciones que faciliten conocer si nuestra alimentación es la correcta para mantenernos sanos y con nuestras defensas naturales en buena forma.

\section{TABLA 3}

Alimentos con abundancia de vitaminas hidrosolubles: Fruta fresca, verduras, tubérculos, carne y productos lácteos.

Alimentos con abundancia de vitaminas liposolubles:

Verduras, aceites vegetales, legumbres, carnes, algunos pescados y huevos.

Alimentos que contienen antioxidantes:

Vit. A: frutas, verduras, clara de huevo, pescado, queso.

Carotenoides: zanahorias, verduras.

Vit. E: aceites vegetales, trigo integral, brócoli, almendras, salmón.

Vit. C: frutas y verduras (crudas y frescas)

Selenio: carne(riñones e hígado), pescado, ajos.

Zinc: carnes, cereales integrales, legumbres, ostras.

\section{Consejos generales para que la dieta sea adecuada}

Las comidas deben repartirse de forma que no interfiera la digestión con la actividad física. En general, desayuno abundante (un 25\% del total calórico diario) y una comida equilibrada con la cena, servirán como modelo a seguir. La comida de precompetición, ligera, con ingredientes conocidos y que no tenga muchas grasas, proteínas y ali- 
mentos crudos, para suavizar la digestión. Debe hacerse, al menos 3 horas antes de comenzar el calentamiento previo a la competición.

Como pautas generales, el desayuno con muchos carbohidratos complejos (cereales), leche desnatada, zumos de frutas, yogurt o queso fresco. Comida con un plato de carbohidratos complejos (legumbres, verduras, arroz, pasta), otro de proteínas (carne, pescado, huevos) y fruta de postre. De cena, alternar los contenidos de la comida, pero con la misma pauta y quizás cambiando la fruta por yogurt o cuajada. Beber mucha agua a todas horas, aunque no se tenga sed.

En la variedad de los ingredientes de nuestra alimentación, no solamente está el gusto, sino la salud.

\section{Bibliografía}

BENDER, D.A.: "Introduction to nutrition and metabolism" (1993) UCL Press.

Brouns, Fred: «Nutritional needs of Athletes» (1993) John Wiley \& sons.

BURKE, L.: "The complete guide to food for sports performance» (1992) Allen \& Unwin.

Burke L., Deakin, V.: “Clinical Sports nutrition" (1994) McGraw - Hill Co.

DAvidson, Passmore: «Human nutrition and Dietetics» (1986) Churchill Liv.

JENKENDRUP, Asker, E.: «Efficacy of different carbohydrate sources to supply energy during exercise" (1999) Insider 7, 2, 1-6.

KATCH, F.I. and MCARDLE, W.D.: “Introduction to nutrition, exercise and health» (1993) Lea-Febiger.

Maughan, Ron et al.: «Biochemistry of exercise» (1998) Oxford University Press.

Odriozola, José María: «Nutrición y deporte» (1993) Ed. Eudema.

Tolonen, M.: "Vitamins and Minerals in health and nutrition" (1990) Ellis Horwood. 